\title{
Brian Dominance: Whole Brain Theory Based Brain Quadrants among King Saud University Students
}

\author{
Ahmad M. Alghraibeh1, Bander N. Alshalawi² \\ ${ }^{1}$ College of Education, Department of Psychology, King Saud University, Riyadh, KSA \\ ${ }^{2}$ Undergraduate Student, College of Education, Department of Psychology, King Saud University, Riyadh, KSA \\ Email: aalghraibeh@KSU.EDU.SA
}

How to cite this paper: Alghraibeh, A.M. and Alshalawi, B.N. (2019) Brian Dominance: Whole Brain Theory Based Brain Quadrants among King Saud University Students. Open Access Library Journal, 6: e5293.

https://doi.org/10.4236/oalib.1105293

Received: February 25, 2019

Accepted: March 19, 2019

Published: March 22, 2019

Copyright $\odot 2019$ by author(s) and Open Access Library Inc.

This work is licensed under the Creative Commons Attribution International License (CC BY 4.0).

http://creativecommons.org/licenses/by/4.0/

\section{(c) (i) Open Access}

\begin{abstract}
The aim of the study was to examine the whole brain theory-based brain quadrants, and whether each of these is different according to gender. To achieve the aims of the study, whole brain theory-based brain quadrants test will be used. To verify the validity of the test, specialists' agreement was used. For reliability, test reliability coefficients were used. The study seeks to achieve the following objectives: examine the dominating brain quarter among the study sample, and to clarify the differences in the whole brain theory-based brain quarters according to gender.
\end{abstract}

\section{Subject Areas}

Psychology

\section{Keywords}

Brain Quadrants

\section{Background}

The concept of brain hemisphere dominance dates back to the neurologist John Jackson as he introduced his idea of The Leading Hemispheres. This concept is the origin for the development of Brain Dominance ideas. From this, it can be noted the interest of educators from the different levels, whether in basic or secondary schools, or even university level in this significant variable and its contribution in learning and thinking by examining the correlations between learning styles, thinking and the functions assumed by the two brain hemispheres [1]. 
Whole Brain Theory introduced by Herrmann came to present a new conceptions to understand brain functions using the Four Quadrant Model [2] as he divided the brain into Left Made Thinking Processes, which in turn was divided into two sections: The upper left brain (Q-A) - this indicates that the individual prefers the activities containing analysis, thorough examination, guessing and logical problem solving to reach facts. It also includes the decision making based on specific logical assumptions. Q-A individuals prefer simplifying what is complex, calcifying the ambiguous and giving special consideration to the value of time. Therefore, they always wish to complete the tasks in hand as soon as possible using the easiest way to come up with the solutions. They avoid being emotional and this makes them prefer loneliness, and is more prone to being arrogant and ignore human feelings; they prefer linear thinking styles, but, they are brilliant in their own way. As for the second type, Lower Left Brain (Q-B), individuals with this type depend on rules and regulations as they take special consideration to them, especially those rules and regulations that have been proven to be effective and right. Nonetheless, they fight progressive thinking, refuse innovation. The effectiveness of Q-B is highly related with tasks completion without any shortcuts at the time of tasks completion, while focusing on doing these tasks the right way. They focus on one thing until it is finished, then, move to the next task. Being accurate is something sacred for them and they are geniuses in system achievement.

As for Right Made Thinking Processes, this aspect includes the following two sections: the first is Lower right brain (Q-C) and is described as a sponge taking experiences related to mode. It is a sensitive and delicate parameter of moment to moment things; it is pre-equipped with tooth as it is the case for (Q-A) personality, but it is emotional states related truth. Individuals with such personality immediately make mode change and response to it calmly. For him, emotions and spirituality give us a sense of belonging to this word. Therefore, he has an innate internal feeling that people belong to one spiritual family, that our existence on earth is only for human purposes such as being emotional and compassionate. There is no importance for any purposes if they contradict the idea of being human unifying us as groups. As for the second, which is upper right brain (Q-D), this style means that the personality is ambiguous. The conversation used by these individuals is based on analogies without giving an explanation about how these analogies help in clarifying what is being set. This personality is characterized by listening to new ideas, contradiction and questions that are taken for granted or superficial but they indeed hit the heart of the subject. The individual with such personality is imaginative, artistic and puzzling from time to time [2].

Previous studies examining the difference between male and female brain have focused on the whole brain size as there is a difference between brain size of male and female at birth. At birth, the male brain is larger than the female and the brain circumference for males is bigger by $2 \%$ compared to females. Also, the 
left brain hemisphere develops at earlier ages compared to right brain hemisphere among female while the right brain hemisphere develops at earlier ages among females and these differences play a vital role in class discipline and mathematical preferences [3].

It seems that the study of brain quadrant based on brain hemisphere is still scare if a difference between males and females in thinking styles is assumed, especially when knowing that brain physiology is evident between the two. In the respect, De Boer and Berg [4] studied the dominant brain quadrant based on Herrmann brain dominance theory. The sample of the study consistent of (68) students enrolled in criminology course at Pretoria university. For data collection and to identify learning and thinking styles among students, Herrmann brain dominance test was used. The results of variance analysis indicated that students are equally distributed on the four learning and thinking styles $(\mathrm{Q}-\mathrm{C}$, $\mathrm{Q}-\mathrm{B}=\mathrm{Q}-\mathrm{A}=\mathrm{Q}-\mathrm{D})$.

In another study, Zainal, Shuib and Othman [5] worked to identify the most and least preferred thinking and learning styles among a sample of Sains University in Malaysia. The sample of the study consistent of (30) male and female students in science and arts departments. Herrmann brain dominance test was used to identify the preferred learning and thinking styles among students. The analysis result indicated that students use left brain hemisphere in their learning more than right hemisphere, especially in (Q-A) quadrant as they prefer analytical and logical thinking style, while students with (Q-D) prefer creative and intuitive thinking style.

Noffal and Abu-Awad [6] investigated the psychometric properties of Herrmann brain dominance test which they used to identify brain dominance style among university colleges students. The Herrmann brain dominance test was adapted on the Jordanian culture among a sample of (500) male and female Jordanian university students. Validity and reliability of the test were verified. The result of the study indicated that generally, students use lower left hemisphere brain dominance $(\mathrm{Q}-\mathrm{B})$, then followed by upper left hemisphere brain dominance (Q-B).

In his study, Minotti [7] tested the use of individual homework assignment based on learning and thinking styles and their effect on academic achievement. The sample of the study consistent of (181) sixth, seventh, and eight school students selected from an urban parish school in New York. Some of the students were given homework assignment based on learning and thinking styles while the others were given instructions about the use of traditional study strategies. The group given homework assignment based on learning and thinking styles showed more academic achievement and new directions with age.

While Lahnakoski and his colleagues [8] examined brain networks and social perspective in the normal conditions. The sample of the study totaled (90) healthy individuals who were subjective to (fMRI). The result of the study indicated the existence of four separate regions processing social science: 1) A 
fronto-temporal network-response to multiple social groups, 2) A fronto-parietal network-a preferential activation of movement and pain, 3) Temporo-amygdala network-recognizing faces, social interaction and speech, 4) A fronto-insular network-responding to pain, emotions, social interactions and speech.

Sulimanand Al-ghraibeh [9] explored the predictable correlation between hemisphericity (right, left and integrated) and reaction time. Two instruments were utilized-the reaction time machine and the hemisphericity scale. Instruments' validity and reliability were insured. Fifty-four students were randomly assigned to participate in the study; their age mean was 21.4 years. Results proved that was significant differences were found between left hemisphere and both the right hemisphere and the integrated brain in favor of the left hemisphere; a correlation was found between hearing reaction time and both the left hemisphere and the integrated brain. A statistical effect was found on the left hemisphere, the integrated brain on hearing reaction time.

Alghraibeh, \& AL-Jomah [10] studied brain quadrant and social media use for academic purposes. To achieve the objective of the study, two measures were used after specialist validity and reliability coefficient were obtained. The sample of the study totaled (634) male and female students enrolling in Saudi, Egyptian and Algerian universities for in the academic year 2014-2015. Students of each country were selected using cluster stratified sampling procedure. The result of the study indicated that the means score for social media used among university students was $(\mathrm{M}=3.37)$.

As seen in previous studies, there is paucity - to the researcher knowledge-in studies focusing on brain dominance related to brain quadrant. For this reason, this study came to use brain dominance test based on whole brain theory to identify the prevalent level of brain quadrant and whether there are differences in prevalent level of brain quadrant according to age.

\subsection{Study Problem}

The problem of the study may be stated in its attempt to identify the prevalent level of brain quadrant and whether there are differences in prevalent level of brain quadrant according to age. Specifically, the study attempts to answer the following questions:

1) What is the prevalent level of brain quadrant among study sample?

2) Are there differences in prevalent level of brain quadrant according to age?

\subsection{Significance}

The significance of the study emerges from the fact that the study of brain quadrant based on whole brain theory among individuals is one of the new research directions proving its importance in cognitive psychology as the success of an individual and his progress in life mainly depends on the cognitive preferences one uses. Determining preference style may help in making several important decisions in the education field such as learning acceleration, student promotion 
to higher classes or his early entry to school. If the brain development is not at the optimal level, such decisions are not recommended. Furthermore, it is possible to provide clear indicators consider the type of training a student needs.

Having more information about whole brain function techniques helps him reconsidering curricula planning. Additionally, identifying differences between males and females in brain quadrant use preferences may contribute in further examinations about the causes of such differences and to develop suitable educational and physiological programs for each group. From this point, it is obvious the need for further studies to come out with clearer results about the nature of such a relationship.

\subsection{Procedural Definitions}

Brain quadrant based on whole brain theory: individual's use of one of the four brain quadrant in mental operations. It is measured by the respondent means score on brain quadrant test.

\subsection{Study Variables}

The study included the following variables:

- Gender (Male, Female).

- Prevalent brain quadrant (Q-A, Q-B, Q-C, Q-D).

\subsection{Limitations of the Study}

The sample of the study was confined to King Saud University students. Furthermore, the results obtained were limited by the psychometric properties of brain quadrant test based on whole brain theory and this means that the results of this study will only be generalized to the statistical population used in this study and other similar populations.

\section{Method}

\subsection{Participants}

The study included King Saud University students as the sample of the study was selected using random sampling (Table 1).

\subsection{Measures}

The instrument on the study was a Herrmann Brain Dominance Instrument (HBDI) consisting of (120) items which is developed based on Whole Brain

Table 1. The distribution of the study sample according to gender and age.

\begin{tabular}{|c|c|c|c|}
\hline \multirow{2}{*}{ Statistics } & \multicolumn{2}{|c|}{ Gender } & \multirow{2}{*}{ Overall } \\
\hline & $\mathbf{M}$ & F & \\
\hline Number & 310 & 340 & 650 \\
\hline percentage & 47.70 & 52.30 & 49.1 \\
\hline
\end{tabular}


Theory. The test was adopted by "She" to the Chinese culture to include (60) items descripting a serious of learning activities that can be preferred by students while learning. The items are equally distributed on each of the brain quadrant, (15) items for each and is divided according to Herrmann Theory [2] into four learning and thinking styles, which are upper left brain (Q-A), lower left brain (Q-B), lower right brain (Q-C) and upper right brain (Q-D).

\subsubsection{Validity and Reliability}

Content and face validity of the instrument were obtained by giving the final format of the test before administration to a panel of (8) experts (faculty members) and their remarks were taken in consideration. To obtain reliability, the test was administrated to a sample of (30) male and female students. After a two weeks interval, the same test was administrated to the same group of students, and Cronbach Alpha coefficient were calculated (Pearson Coefficient). The total reliability coefficient for the instrument was $(0.82)$ and for the individual domain as follows: (Q-A: 0.71; Q-B: 0.70; Q-C: 0.76; Q-D: 0.74). Also, internal consistency for the test were calculated using Cronbach Alpha as total reliability coefficient for the instrument was (0.85) and for the individual domain as follows: (Q-A: 0.70; Q-B: 0.72; Q-C: 0.76; Q-D: 0.69).

\subsubsection{Correcting Procedure}

The number of items correctly responded by the students within each quadrant were computed to calculate the total score of the respondent and their score for each domain of the instrument (quadrant).

\subsection{Study Procedures}

An official authorization from the university was obtained so as the researcher administrates the instrument of the study to the target students in the selected faculties. Furthermore, the brain quadrant test based on Whole Brain Theory was administrated.

\subsection{Statistical Analysis}

Numbers and percentages for each level of the prevalent brain quadrant levels were calculated. Also, observed percentages within each level of the prevalent brain quadrant levels were calculated. Furthermore, percentages of the total frequency and the standard residual for the study sample categorized within the prevalent brain quadrant levels according to gender (male, female), Chi square was calculated. The following is the result of the study according to its questions.

\section{Results}

To answer the first question: "What is the prevalent level of brain quadrant among study sample?", frequencies and percentages for the study sample within each of the brain quadrant use level were calculated. Table 2 shows these results.

As seen in Table 2, 32.3\% of the study sample use upper left brain quadrant 
Table 2. Frequencies and percentages for the study sample within each of the brain quadrant use level.

\begin{tabular}{ccccccccc}
\hline \multirow{2}{*}{ level } & \multicolumn{2}{c}{ Q_A } & \multicolumn{2}{c}{ Q_B } & \multicolumn{2}{c}{ Q_C } & \multicolumn{2}{c}{ Q_D } \\
\cline { 2 - 8 } & Number & percentage & Number & percentage & Number & percentage & Number & percentage \\
\hline low & 130 & 20 & 145 & 22.3 & 170 & 26.2 & 140 & 21.4 \\
mid & 370 & 56.9 & 360 & 55.4 & 270 & 41.5 & 330 & 50.8 \\
high & 150 & 23.1 & 125 & 19.2 & 210 & 32.3 & 180 & 27.8 \\
total & 650 & 100.0 & 650 & 100.0 & 650 & 100.0 & 650 & 100.0 \\
\hline
\end{tabular}

(Q-A) with high level, while $27.8 \%$ of the study sample use lower left brain quadrant (Q-B) with high level; $23.1 \%$ of the study sample use lower right brain quadrant (Q-C) with high level, and $19.2 \%$ of the study sample use lower right brain quadrant (Q-D) with high level.

To answer the second question: "Are there differences in prevalent level of brain quadrant according to age?", frequencies and percentages for the study sample within each of the brain quadrant use level according to age were calculated, in addition to use Chi square to identify the significant differences between males and females on brain quadrant use level. Table 3 shows frequencies and percentages according to gender.

As seen in Table 3, there were statistically significant differences at $(\alpha=0.05)$ between the frequencies within the use level of upper left brain quadrant due to gender as it can be noted that male students use upper left brain quadrant more compared to females which indicates that males outperformed females in the use upper left brain quadrant.

\section{Discussion}

Discussing the results of the first question stating: "What is the prevalent level of brain quadrant among study sample?"

The result of the first question indicated that the highest level of brain quadrant (Q-C) with a means score of $32.3 \%$, followed by (Q-D) with a means score of $27.8 \%$.

The lower right brain quadrant (Q-C) and the upper right brain quadrant (Q-D) are considered the main source of emotional feeling. As emotions are important for thinking and learning, each of the brain hemisphere has specific functions. As for emotional aspects, the right brain hemisphere is responsible for processing emotional features such as laughter and forgiveness [11]. As seen in the result reported in this study, there is a high use level for the lower right brain quadrant $(\mathrm{Q}-\mathrm{C})$ and the upper right brain quadrant (Q-D), which represent the right brain hemisphere known as being responsible of emotional responses and it is related with intuition, feelings, creativity and imagination. It also activates visual information and material, musical material in addition to responding to emotional stimuli. It is also the hemisphere that recognizes faces at much higher degrees and contains feelings of joy [12]. 
Table 3. Frequencies and percentages for the study sample according to gender within each of the brain quadrant use level.

\begin{tabular}{|c|c|c|c|c|c|c|c|c|c|}
\hline \multirow{2}{*}{$\begin{array}{l}\text { Learning } \\
\text { style }\end{array}$} & \multirow{2}{*}{ Gender } & \multirow{2}{*}{ Statistics } & \multicolumn{3}{|c|}{ Dominance level. } & \multirow{2}{*}{ Total } & \multirow{2}{*}{$x^{2}$} & \multirow{2}{*}{ df } & \multirow[b]{2}{*}{$\mathrm{p}$} \\
\hline & & & low & mid & high & & & & \\
\hline \multirow{4}{*}{ Q_A } & $M$ & No. & 55 & 170 & 85 & 310 & \multirow{4}{*}{13.981} & \multirow{4}{*}{2} & \multirow{4}{*}{0.001} \\
\hline & 102 & Percentage & 17.74 & 54.8 & 27.4 & 100.0 & & & \\
\hline & \multirow{2}{*}{ F } & No. & 40 & 244 & 56 & 340 & & & \\
\hline & & Percentage & 11.8 & 71.8 & 16.5 & 100 & & & \\
\hline \multirow{4}{*}{ Q_B } & \multirow{2}{*}{$\mathbf{M}$} & No. & 66 & 170 & 74 & 310 & \multirow{4}{*}{15.574} & \multirow{4}{*}{2} & \multirow{4}{*}{0.000} \\
\hline & & Percentage & 21.3 & 54.8 & 23.9 & 100 & & & \\
\hline & \multirow{2}{*}{ F } & No. & 81 & 190 & 69 & 340 & & & \\
\hline & & Percentage & 23.8 & 55.9 & 20.3 & 100 & & & \\
\hline \multirow{4}{*}{ Q_C } & \multirow{2}{*}{$\mathbf{M}$} & No. & 62 & 171 & 77 & 310 & \multirow{4}{*}{3.341} & \multirow{4}{*}{2} & \multirow{4}{*}{0.188} \\
\hline & & Percentage & 20 & 55.1 & 24.8 & 100 & & & \\
\hline & \multirow{2}{*}{ F } & No. & 55 & 189 & 96 & 340 & & & \\
\hline & & Percentage & 16.2 & 55.6 & 28.2 & 100 & & & \\
\hline \multirow{4}{*}{ Q_D } & \multirow{2}{*}{ M } & No. & 49 & 185 & 76 & 310 & \multirow{4}{*}{1.617} & \multirow{4}{*}{2} & \multirow{4}{*}{0.446} \\
\hline & & Percentage & 15.8 & 59.7 & 24.5 & 100 & & & \\
\hline & \multirow{2}{*}{ F } & No. & 70 & 180 & 90 & 340 & & & \\
\hline & & Percentage & 20.6 & 52.9 & 26.5 & 100 & & & \\
\hline
\end{tabular}

The use of left brain hemisphere (Q-A, Q-B) may be explained also as being the center of language skills [12]. Students within the age group (12 - 16) are dealing with a lot of educational experiences requiring the use of language intensively. As such, the brain hemisphere activity is dependent on the nature of tasks and activities process and engaged by the individuals [13].

The prevalent teaching methods in schools enhance the reliance of left hemisphere brain dominance among students as the majority of teachers focus in their teaching on developing the left brain hemisphere functions which represent information processing in a sequential, linear, symbolic, logical and verbal method. Furthermore, the left brain hemisphere relies on using information processing on logic and truth [14] [15].

Discussing the result of the second question stating: "Are there differences in prevalent level of brain quadrant according to age?"

The result of the study indicated there is a statistically significant difference at ( $\alpha=0.05$ ) between the frequencies within the use level of upper left brain quadrant (Q-A, Q-B) due to gender as differences were in favor of males in the higher level of upper left brain quadrant (Q-A, Q-B).

Taking the fact that male brains are more prone to determine language in the left brain hemisphere while female brains use integrated brain hemisphere [16], and the fact that upper left brain quadrant (Q-A) and lower left brain quadrant (Q-B) focus more on problem solving, and observing the geometric features of words and verbal intelligence, establishing habits and maintaining them any by 
believing in that males outperform females in this aspect, and by examining learning and teaching strategies used by teachers which mainly focus on the functions relating to the left brain hemisphere such as ordering, organizing, sequencing and math; as they are all left brain hemisphere functions and considering the fact that males are more favorable of using logic and rationality when managing the different issues [17], the conclusion is that males outperform females in the left brain hemisphere. Also, school curricula developed based on solving complex problems in mathematics and science are more suitable for males compared to females [18].

\section{Recommendations}

Based on the result, some recommendations were suggested, including:

1) Further research for the causes of differences between males and females and developing appropriate programs for each.

2) Future research examining brain dominance using variables relating to the psychological domains of different age groups are needed.

\section{Compliance with Ethical Standards}

This study was conducted with approval from the responsible ethics committee (King Saud University, Ministry of education) and in accordance with national law and the Helsinki Declaration of 1975 (in its current, revised form). Informed consent was obtained from all participants.

\section{Acknowledgements}

We extend our appreciation to the Deanship of Scientific Research, King Saud University for funding this work through the Undergraduate Student's Research Support Program (project No. USRSP-17-54).

\section{Conflicts of Interest}

The authors declare no conflicts of interest regarding the publication of this paper.

\section{References}

[1] Shelnutt, J., Middleton, S., Buch, K. and Lumsdain, M. (1996) Forming Student Project Teams Based on Herrmann Brain Dominance (HBDI) Results. ASEE Annual Conference, Washington DC, 23-26 June 1996, 1.219.1-1.219.7.

[2] Herrmann, N. (1995) The Creative Brain. Quebecor Printing Book Group, USA.

[3] Jensen, E. (1998) Teaching with the Brain in Mind. Association for Supervision and Curriculum Development. Science Teachers Association, Alexandria, VA.

[4] De Boer, A.L. and den Berg, D.V. (2001) The Value of the Herman Brain Dominance Instrument (HBDI) in Facilitating Effective Teaching and Learning Criminology. Acta Craniologica Journal, 14, 120-129.

[5] Zainal, Z., Shuib, M. and Othman, M. (2004) Thinking Styles. Malay, US.

[6] Noffal, M. and Abu-Awad, F. (2007) The Psychometric of Ned Herman (HBDI) and 
its Effectiveness in Detecting the Pattern of Brain Control in a Sample of Jordanian University Students. Jordanian Journal of Educational Sciences, 3, 143-163.

[7] Minotti, J.L. (2005) Effects of Learning-Style-Based Homework Prescriptions on the Achievement and Attitudes of Middle School Students. NaSSP Bulletin, 89, 67-89. https://doi.org/10.1177/019263650508964206

[8] Lahnakoski, J.M., Glerean, E., Salmi, J., Jääskeläinen, I.P., Sams, M., Hari, R. and Nummenmaa, L. (2012) Naturalistic FMRI Mapping Reveals Superior Temporal Sulcus as the Hub for the Distributed Brain Network for Social Perception. Frontiers in Human Neuroscience, 6, 233. https://doi.org/10.3389/fnhum.2012.00233

[9] Aljomaa, S.S.A. and Alghraibeh, A.M.A. (2016) Hemisphericity (Right, Left and Integrated) as a Predictor of Reaction Time. European Journal of Scientific Research, 141, 445-457.

[10] Alghraibeh, A.M. and Al-Jomah, S.S. (2018) Preferences of Brain Quadrants and the Use of Social Networks for the Purpose of Learning: Cross Cultural Study. Journal of Educational \& Psychological Sciences, 19, 11-39.

[11] Bruck-Kan, R. (1979) Introduction to Human Anatomy. Harper \& Row.

[12] Annett, M. (1998) Handedness and Cerebral Dominance: The Right Shift Theory. The Journal of Neuropsychiatry and Clinical Neurosciences, 10, 459-469. https://doi.org/10.1176/jnp.10.4.459

[13] Petty, G.C. and Holtzman, F. (1991) Learning Styles and Brain Hemisphericity of Technical Institute Students. Journal of Studies in Technical Careers, 13, 79-91.

[14] Sousa, D. (2001) How the Brain Learns. National Association of Secondary School Principles, Reston, VA.

[15] Crawford, A., Saul, W. and Mathews, S.R. (2005) Teaching and Learning Strategies for the Thinking Classroom. IDEA.

[16] Radford, J., Ed. (1998) Gender and Choice in Education and Occupation. Psychology Press, USA.

[17] Albaili, M.A. (1993) Inferred Hemispheric Thinking Style, Gender, and Academic Major among United Arab Emirates College Students. Perceptual and Motor Skills, 76, 971-977. https://doi.org/10.2466/pms.1993.76.3.971

[18] Sylwester, R. (1997) Applying Brain/Stress Research to Classroom Management. Association for Supervision and Curriculum Development. 